\title{
Todo fálico e não-todo: construções lacanianas sobre a sexuação
}

\section{All phallic and non-all: Lacan elaborations about the sexualization}

Flavia Bonfim*

Consultório particular, Niterói, Rio de Janeiro, Brasil

\begin{abstract}
RESUMO
O interesse deste ensaio é apresentar o avanço teórico produzido por Lacan a partir da introdução da lógica em torno do problema da sexuação, no qual ele delimitou de forma precisa o posicionamento masculino e feminino por meio de suas modalidades de gozo. É, então, com suas famosas fórmulas da sexuação que o ensino lacaniano articula a diferença anatômica sob a oposição de duas lógicas (a do todo-fálico nos homens e do não-todo nas mulheres) e também duas espécies distintas de gozo (o fálico e o suplementar). Tais construções revelam uma virada decisiva na abordagem da feminilidade, no qual está em evidência a formalização do além do Édipo - uma maneira de aceitar a proposição edípica, mas também de apontar que em seu horizonte só podemos reconhecer a lógica do todo-fálico, que produz a posição masculina, mas não a feminina.
\end{abstract}

Palavras-chaves: sexuação, todo-fálico, não-todo, gozo fálico, gozo suplementar.

\section{ABSTRACT}

The interest of this paper is to present the theoretical advances made by Lacan from the introduction of a logic around the problem of sexualization, in which he delineated the precise way the masculine and feminine positioning by their mode of enjoyment. It is, then, with his famous sexualization formulas that Lacan teaching articulates the anatomical difference under the two opposing logics (the all-phallic in men and not-all in the women) and too two distinct species of enjoyment (the phallic and supplemental). Such constructions show a decisive turning in the approach of femininity, which is in evidence the formalization of the Oedipus beyond a way to accept the Oedipus proposition, but also to point out that on the horizon we can only recognize the logic of all-phallic, that produces the male position but not in feminine.

Keywords: sexualization, all-phallic, not-all, phallic jouissance, supplementary jouissance.

\section{I ntrodução}


Freud inaugura o campo psicanalítico e com isso se abre uma problemática inerente à sexualidade. Neste contexto, noção de primazia fálica serve-lhe para responder a questão da constituição masculina e feminina. Diante disso, ele pondera que a posição sexual do sujeito é construída, no caso do homem, mediante o medo de perder o falo e da mulher, na vontade de tê-lo. Postular tal consideração rendeu-Ihe a crítica de adotar uma teoria "falocêntrica" por parte de seus próprios seguidores, entre eles: Melanie Klein, Ernest Jones, Helene Deutsch e Karen Horney - para citar os mais eminentes, como enumera Lacan. Assim, entre a década de 1920 e 1930, surge um fervoroso debate dos pós-freudianos em torno, sobretudo, de uma recusa em considerar a falta fálica como sendo o núcleo da feminilidade.

O ensino lacaniano em seu "retorno a Freud", mais especificamente no escrito "A significação do falo" (1958) retoma esse debate para com ele estabelecer o falo como o significante estruturador da sexualidade, seja ela masculina ou feminina. Na ausência de um instinto que acarretaria certo saber sobre a sexualidade, o sujeito tem apenas um significante, um recurso puramente simbólico, que une sexualidade e linguagem, permitindo ao sujeito se situar em relação à partilha dos sexos. Não é à toa que, frente a isso, a relação sexuada seja marcada por tanta complicação para o humano.

Mediante as considerações lacanianas sobre os desvios na obra de Freud cometidos pelos seus seguidores, observamos, a posição inicial de Lacan em salvaguardar as formulações freudianas sobre a primazia fálica. Todavia, não podemos nos esquecer do questionamento introduzido por Lacan no texto de 1958, "Diretrizes para um congresso sobre a sexualidade feminina", que abrirá caminho para as suas construções posteriores a respeito do gozo feminino não-todo referido ao falo. Nesse texto, ele escreve: "convém indagar se a mediação fálica drena tudo o que pode se manifestar de pulsional na mulher, notadamente toda a corrente do instinto materno." (Lacan, 1998b, p.739) No mesmo texto, Lacan, após fazer um comentário de que a castração não pode ser deduzida apenas do desenvolvimento, na medida em que depende da subjetividade do Outro como lugar de sua lei, escreve: "O homem serve aqui de conector para que a mulher se torne esse Outro dela mesma, como o é para o homem." (ibid., p. 741). Márcia Rosa (2001) identifica que nesta "afirmação", Lacan "antecipa o não-todo dos anos setenta." (2001, p. 58) ou seja, ele antecipa a discussão que se colocou de modo particular no Seminário 20 - Mais ainda e no texto "O aturdito".

Verificamos, com isso, que a indagação sobre o gozo feminino já havia sido colocada por Lacan desde 1958 no referido artigo, contudo, segundo André (1998), foram precisos quatorze anos para que ele pudesse respondê-la de modo mais preciso no Seminário 20 
com o objetivo de esclarecer o obscurantismo que pairava sobre a questão da sexualidade feminina no meio psicanalítico. Isso, no entanto, não quer dizer que neste meio tempo, Lacan não tenha dado algum indício do que viria a elaborar na década de 70 .

Tomemos o exemplo do que ele diz no "Seminário 10 - A angústia":

A mulher revela-se superior no campo do gozo, uma vez que seu vínculo com o nó do desejo é bem mais frouxo. A falta, o sinal menos com que é marcada a função fálica no homem, e que faz com que sua ligação com o objeto tenha que passar pela negatividade do falo e pelo complexo de castração, o status do (- $\Phi)$ no centro do desejo do homem, é isso que não constitui para a mulher um nó necessário. (Lacan, 2005, p. 202, grifo do autor)

De acordo com André (1998), Lacan, no Seminário 20, basea-se em duas constatações: a primeira, que Freud e seus discípulos não conseguiram dar nenhum passo sobre a questão do gozo feminino; a segunda, que a feminilidade é uma problemática de um ser que não pode se assujeitar inteiramente ao Édipo e à lei da castração. É nesse contexto que Lacan reconhece que a mulher está inscrita na lógica fálica, contudo, nos diz que ela não está totalmente submetida a ela. Sendo assim, a diferença anatômica é posta sob a oposição de duas lógicas (a do todo-fálico nos homens e do não-todo nas mulheres) e também a duas espécies distintas de gozo (o fálico e o suplementar). Tais construções revelam uma virada teórica decisiva na abordagem da feminilidade, no qual está em evidência uma formalização do além do Édipo - uma maneira de aceitar a proposição edípica, mas também de apontar que em seu horizonte só podemos reconhecer a lógica do todo-fálico, que produz a posição masculina, mas não a feminina.

Collete Soler (2005) argumenta que a história edipiana responde a pergunta de como pode um homem amar sexualmente uma mulher, obtendo como resposta: por meio da renúncia à mãe e ao gozo referido a ela, ou seja, através da castração do gozo. Soler acrescenta que Freud tentou utilizar explicação semelhante para o lado feminino, contudo, ao final, reconheceu seu fracasso quando indagou o famoso "o que quer a mulher?", que ela traduz como: "o Édipo produz o homem, não produz a mulher". (2005, p. 17). Ainda segundo Soler, as "elaborações inovadoras" de Lacan, contida no Seminário 20, foram acompanhadas por uma "denúncia, discreta e decente, mas explícita e vigorosa" (2005, p.15) a respeito do "forçamento" freudiano de transpor para as mulheres o que se referia aos homens, entretanto, observa ela, que Lacan, mesmo interrogando e criticando o Édipo freudiano, não o refutou 
completamente. Freud situou a questão da sexualidade em torno do Édipo e das implicações psíquicas do medo de perder o falo e do desejo de tê-lo. Por sua vez, o ensino lacaniano não recusa o falo como o único significante da sexuação, porém, extrai as implicações desse fato para a mulher. Nesse sentido, temos que "O falo - como significante da falta - funciona como um véu que encobre a castração e relança um mais além." (Costa, 2008, p. 313). Com isso, Lacan conseguiu formular soluções para onde o pensamento freudiano se confrontou com impasses e dificuldades.

O ensino lacaniano, então, nos introduz no campo da sexuação. Este termo, escreve Soler, "identifica o homem e a mulher, em última análise, por sua modalidade de gozo." (2005, p. 138) A modalidade de gozo, por ação de linguagem, fica no âmbito da castração, existindo duas maneiras distintas de se inscrever na função fálica. Estar totalmente submetido à função fálica implica que este sujeito é homem - o que o garante ter a castração e o gozo fálico como destino, ao qual terá acesso por meio da fantasia. É mulher, o sujeito que está não todo submetido à função fálica, tendo, por isso, acesso a um gozo suplementar e, portanto, sem nenhum suporte de objeto ou semblante. Isto é pura consequência do fato da anatomia não ser capaz de assegurar ao sujeito uma posição sexual. Ela decide o registro civil, mas não comanda o desejo e a pulsão. $O$ pênis é o marcador de uma diferença, sua presença ou ausência implica em alguém ser chamado de menino ou menina - o que leva, por conseguinte, a ser doutrinado segundo cada modelo social do que "é ser homem" e o que "é ser mulher". Tais modelos identificatórios são frágeis e será preciso mais para tornar o menino um homem e a menina, uma mulher. Nesse sentido, Soler afirma: "Os sujeitos se identificam tão pouco com sua anatomia, que se inclinam mais a se inquietar com seu ser sexuado." (2005, p. 136) Continuando, a psicanalista argumenta que em se tratando de corpos sexuados, 0 discurso é incapaz de corrigir, dar conta, da "desnaturação" sexual do sujeito. O que temos é apenas o semblante fálico para ser oferecido nesta substituição, cuja a diferença natural dos sexos só adquire conseqüências subjetivas ao ser significantizada. (Soler, 2005)

Afinando-se isso, mas, de maneira mais detalhada, Morel (1997) apresenta a sexuação por meio de uma lógica em três tempos: 1) Tempo da diferença natural entre os sexos; 2) Tempo do discurso sexual; 3) Tempo da escolha do sexo pelo sujeito (a sexuação propriamente dita). Nesse sentido, sigo servindo-me das considerações desta psicanalista. O primeiro tempo é mítico e trata da diferença anatômica entre os sexos. Este, porém, só assumirá seu valor no tempo dois, pois no ser humano a natureza só tem sentido na medida em que é interpretada. Sobre o anatômico, diz-se: "é menino" ou " é menina", a partir de um significante, sem o qual é impensável situar qualquer diferença. Sendo menino, é portador do 
pênis, da virilidade, capaz de ser homem. Já como menina, é sinônimo de falta, privação, feminilidade, enigma. É a natureza sob a forma de semblante. Neste caso, temos o discurso do Outro incidindo sobre a definição homem e mulher, no qual o significante fálico escreve os dois sexos em termos binários de falo e castração. Ou seja, um único significante para dois significados diferentes e isso não se dá sem produzir certos efeitos de confusão. Temos, aqui, o discurso produzindo laço a partir do universal do falo. É no terceiro tempo, porém, que tal confusão é solucionada e o sujeito pode fazer a escolha de seu sexo. Isto implica em dizer que o que temos na sexuação é o encontro com uma única função de gozo na linguagem, a função fálica, mas escrita de maneiras distintas: todo fálico e nãotodo fálico - sendo nisto que o instrumento lógico de quantificação é útil a Lacan (Morel, 1997).

Será por meio da formulação lógica, dos seus famosos matemas, que Lacan trabalhará as noções de homem e mulher, reunindo em um quadro as fórmulas quânticas da sexuação - indispensável para discussão do todo e não-todo fálico. Trata-se de um quadro apresentado pela primeira vez no Seminário 20. No "O aturdito", Lacan apresenta estes matemas como "lógica que se resume tudo o que acontece com o complexo de Édipo (2003/1972, p. 458). Referindo-se ao quadro, Lacan comenta que Ihe "parece exemplar senão, como de hábito, para produzir mal-entendido." (1985, p. 106) Logo após tal comentário, ele segue a falar sobre a noção de sentido, propondo-nos que a experiência no discurso analítico faz emergir a idéia de que sentido é aparência, bem como ele próprio conduz ao fracasso. Talvez isso nos permita considerar que "produzir malentendido" vem se opor a um dizer recheado de sentido, que não nos levaria a avançar naquilo que o discurso analítico nos permite articular quanto à sexuação. Se sua compreensão não é oferecida tão facilmente, é com calma e prudência que devemos abordá-lo advertência proposta por Lacan. Tentaremos seguir sua recomendação.

Quem quer que seja ser falante, afirma Lacan, se inscreve de um lado ou do outro do quadro, visto que os matemas revelam "as únicas definições possíveis da parte dita homem e bem mulher para o que quer que se encontre na posição de habitar a linguagem." (Lacan, $1985 / 1972-73$, p. 107). A coluna esquerda descreve a posição masculina e o lado oposto, a feminina. Esta divisão não corresponde à distinção anatômica entre os sexos, mas se trata de uma posição sexuada determinada no próprio discurso do sujeito, muitas vezes em desacordo com sua anatomia. Em ambos os lados, a função $\varphi x$ afirma que aquilo que traz relação com a sexualidade provém da função fálica e, situar-se de um lado ou de outro, depende da maneira como o sujeito está assujeitado a ela. Há também no quadro os "quantificadores". Há dois tipos deles: os quantificadores 
existenciais - $\exists x$ e $\overline{\exists x}$ (que devem ser lidos da seguinte maneira, respectivamente: "existe um" e "não existe um") - e os quantificadores universais - $\forall x$ e $\overline{\forall x}$ (que devem ser lidos, respectivamente: "para todo $x$ " e "para não todo $x$ "). Já o " $x$ ", como já apontamos anteriormente, designa o sujeito.

Realizadas as devidas considerações, vejamos, inicialmente, as inscrições do lado masculino:

$\exists \mathbf{~} \overline{\mathbf{x}} \Rightarrow$ existe um "x", um sujeito, para quem a função $\varphi x$ não funciona, ou seja, existe um homem que não está na castração.

$\forall \mathbf{X} \quad \boldsymbol{\phi X} \Rightarrow$ para todo homem há a inscrição da função fálica. Isto quer dizer que todo homem e o homem como um todo está submetido à castração.

Aqui, percebemos que o que se poderia supor como uma contradição é precisamente aquilo que sanciona a proposição de Lacan quando pensamos na relação existente entre a regra e sua exceção. Esta não somente confirma a regra, como lhe dá seu fundamento. Lacan diz que: "O todo repousa portanto, aqui, na exceção colocada, como termo, sobre aquilo que, esse $\varphi x$, o nega integralmente." (1985/1972-73, p. 107). A exceção, ou seja, o único que escapa à castração, é encarnado pela figura do pai da horda primitiva; logo, a exceção é necessária para que os homens estejam totalmente referidos à castração. Diante disso, Maria Cristina Poli (2008) comenta que a sexuação fálica é sustentada, portanto, por uma estrutura de "ficção".

Agora, tomemos as fórmulas do lado da mulher:

$\overline{\mathbf{3 x}} \overline{\Phi \mathbf{x}} \Rightarrow$ não existe mulher para quem a função fálica não funcione, não há mulher que não esteja assujeitada à castração.

$\overline{\nabla x} \quad \boldsymbol{W} \mathbf{X} \Rightarrow$ para não-todo sujeito é correto afirmar que a função fálica funcione, ou seja, a mulher é não-toda referida à castração, de modo que nem tudo em uma mulher está submetido à lei do significante.

Sobre essa parte do quadro correspondente ao lado feminino, Lacan comenta que "se ele [ser falante] se inscreve nela, não permitirá nenhuma universalidade, será não-todo, no que tem a opção de colocar na $\varphi x$ ou bem de não estar nela." (1985/1972-73, p. 107) Sobre a fórmula $\overline{\nabla \times} \mathbf{c} \mathbf{x}$, ele diz tratar-se de uma função inédita em que a negação recai sobre o quantificador a ser lido como o nãotodo, no qual o ser falante que se situa deste lado funda-se por ser não-todo situado na função fálica. 
Sobre o não-todo feminino, Brodsky esclarece:

Não se trata de mulheres que se inscrevem do lado fálico e outras não: as mulheres se inscrevem não-todas do lado fálico: uma por uma não-toda. A negação do todo feito por Lacan no Seminário 18, formulado pela primeira vez não-toda mulher, afeta dos os universais, tanto afirmativo quanto negativo. $O$ não-todo inclui o nenhum. Não é certo que todas e não é certo que nenhuma, que é outro universal. Não-todo é uma objeção aos dois universais, afirmativo e negativo. Então, uma vez negados os dois universais, algo fica indeterminado. (2008b, p. 483)

Segundo André (1998), $\overline{\mathbf{\Xi x}} \overline{\boldsymbol{\Phi} \mathbf{x}}$ indica que não existe do lado feminino nenhuma figura fundadora de um conjunto de mulheres, visto que nenhuma mulher faz exceção à regra, situando-se fora da castração. Ela não pode ser incluída em um conjunto fechado, mas deverá ser contadas uma a uma. Isso porque existe apenas um significante da sexuação, o falo, de modo que, ao nível inconsciente, o Outro sexuado não existe. "A mulher não existe" - para usar um dos conhecidos aforismos lacanianos. "A mulher, isto só se pode escrever barrando-se o A. Não há A mulher, artigo definido para designar 0 universal." (Lacan, 1985/1972-73, p. 98) Logo, não há um modelo, um significante que forneça um suporte ao ser feminino. A mulher precisa se inventar. Em outras palavras, as mulheres não fazem Um como os homens, mas permanecem em sua infinitude. Sendo assim, cabe aos sujeitos que se situam desse lado, escolher entre recusar ou aceitar a falta de fundamento. Se recusam, acabam por ter que se colocar do lado masculino, encontrando, dessa forma, uma identidade - fálica, é claro. Aceitar a falta de fundamento, suportar a instabilidade do não-todo, é a saída mais difícil, pois incluiu se defrontar que "a mulher não existe", entretanto, é a única via possível para aceder ao posicionamento feminino.

Outro ponto a destacar diz respeito ao modo como a castração se coloca para a mulher, ou seja, dividindo-a, ao contrário do que acontece no ser masculino, que o unifica sob o significante "homem". Dessa maneira, uma mulher sente que uma parte de si está submetida ao gozo fálico (gozo sexual, determinado pelo significante falo), enquanto a outra se situa no gozo Outro, no gozo do corpo (gozo que escapa ao domínio significante). É importante registrar que é a partir do gozo fálico que podemos supor um outro gozo. O gozo fálico, por estar articulado ao significante, nos faz supor que há uma "outra coisa", um "mais-além", na medida em que a função do significante é evocar algo além do que ele diz e produzir seu mais além. Assim, não se pode falar em um gozo Outro senão a partir do 
gozo sexual limitado do órgão. Por sua vez, gozo Outro não é um traço particular do feminino e o gozo fálico, do masculino.

Segundo Bonfim e Vidal (2009) a noção de não-todo

quer dizer que o ser feminino está submetido a um outro gozo, o suplementar, que não está excluído da referência fálica, mas que antes a ultrapassa. A questão principal acerca da feminilidade é como o gozo fálico e o Outro gozo se encontram na mulher. (p. 545).

Desdobrando um pouco mais esse ponto, André (1998) esclarece que, no Seminário 20, a discussão se dá sob uma elaboração que religa dois termos opostos: o significante e o gozo, sendo a intercessão desses dois campos a via utilizada pela teoria lacaniana para situar a questão da feminilidade. O corpo que goza é um corpo afetado pelo significante e é, nesse sentido, que, segundo Lacan, sabemos que um corpo está vivo, porque nele "isso se goza" e "isso só se goza por corporizá-lo de maneira significante." (1985 [197273], p. 35). Em seus termos, o "significante é causa de gozo" (1985 [1972-73], p. 36). Formulado de outra maneira: "a fala faz o corpo onde o sexual acontece." (Caldas, 2008, p. 383) Lacan indica que a realidade é abordada com os aparelhos do gozo e que não há outro aparelho que não seja a linguagem. O gozo é aparelhado pela linguagem. A isto, Lacan acrescenta que, se o inconsciente é estruturado como uma linguagem, é preciso situar que esta linguagem esclarece-se por se colocar como aparelho do gozo do corpo. Por outro lado, Morel assinala que a "linguagem impõe um significante único ao gozo: o falo." (1997, p. 93).

Caldas (2008), por sua vez, assinala que "O significante é precário para dizer da sexualidade. No entanto, paradoxalmente, a sexualidade só aparece e escoa pelo significante. Não é um paradoxo difícil de entender: só temos a desordem, se houver a ordem" ( $p$. 382). O significante produz corpo de gozo, mas não-todo de modo que um resto escapa ao império da linguagem. Paralelamente, podemos propor que o gozo sempre escapa a qualquer tipo de regulação, sendo o significante fálico incapaz de ordenar totalmente o sexual e o campo que ele abre. A mulher, encarnando o real, testemunha, assim, tal impossibilidade. Seu gozo leva em conta o limite, a regulação, mas ao mesmo tempo também o transpõe.

Para nos situarmos um pouco melhor no que se anuncia neste momento do ensino lacaniano, é necessário realizarmos alguns apontamentos sobre a noção de gozo. André (1998) comenta que em "Subversão do sujeito e dialética do desejo no inconsciente freudiano" de 1960, Lacan falava que era preciso distinguir dois tipos de gozo, a saber: o "gozo do ser" e o "gozo sexual" (p. 213). A discussão sobre 
essas duas modalidades de gozo será retomada e desenvolvida por Lacan no Seminário 20, servindo de fundamento para a colocação da problemática feminina. Em 1960, Lacan propunha que o gozo do ser, o gozo em geral, era infinito e que o gozo sexual incidia sobre ele, interditando-o. Isso parecia sugerir que o gozo do ser era prévio ao significante e ao gozo fálico. Entretanto, em 1972, no Mais, ainda, ele introduz uma diferença radical, invertendo a problemática da articulação entre o ser e o significante. Assim, para compreendermos tal diferença introduzida sobre a dialética que envolve o gozo do ser (gozo Outro - como Lacan passa a chamá-lo a partir de então) e o gozo sexual (fálico), correlacionemos, como ele próprio sugeriu, à relação existente entre o ser e o significante. O ser não pré-existe ao significante, mas, ao contrário, é produzido, modelado e determinado por ele. Sem o significante, nada existiria, nem mesmo o ser. Desse modo, podemos dizer que só há gozo (em geral), ilimitado, porque há gozo sexual. Lacan é preciso ao introduzir que "o gozo é marcado por esse furo que não lhe deixa outra via senão a do gozo fálico." (1985/1972-73, p. 16). O gozo fálico é em si mesmo uma delimitação do gozo em geral, mas este não pré-existe àquele. Isso porque sem o significante fálico a dimensão sexual não se introduziria no ser humano, isolando do resto do corpo um órgão privilegiado no campo do sexo (André, 1998).

Contrariando, assim, a proposição freudiana de que a castração coloca obstáculo ao gozo sexual, Lacan afirma que é porque somos castrados que temos acesso ao registro desse gozo. Logo, podemos concluir: o significante fálico introduz uma divisão do gozo, pois ao mesmo tempo em que proíbe um gozo infinito, ele é também responsável por permitir o acesso ao gozo sexual.

O gozo Outro - simbolizado pelo corpo do Outro - será a via pela qual Lacan se utilizará para falar, com certa restrição, do gozo do lado da mulher. Lacan (1985/1972-73) diz que o Outro, na sua linguagem, é o Outro sexo. O gozo Outro é um gozo que escapa ao domínio significante e por isso localiza-se fora-da-linguagem. Em outros termos, nenhuma palavra pode ser dita sobre ele. Dessa maneira, o gozo Outro se opõe ao gozo sexual na medida em que este é determinado pela linguagem, mas precisamente pelo significante fálico. O gozo sexual se situa extracorpo; sua ligação com o corpo se dá por um fio que o une ao órgão sexual. Ao contrário do gozo Outro, ele não sustenta o ser ou o corpo em seu conjunto, apenas certas partes do corpo podem funcionar como equivalente do órgão sexual.

Agora, voltemos nossa atenção para a parte inferior do esquema das fórmulas quânticas da sexuação exposto anteriormente. Lacan (1985/1972-73) diz que a parte inferior do quadro é chamada impropriamente de humanidade, no que ela se repartiria em identificações sexuais. Em seguida, propõe o modo como essas 
partes se relacionam, ou melhor, não se relacionam. Do lado do homem, ele inscreveu o $\$$ e $\circ \varphi$, que o confere suporte como significante, mas nisto, observa ele, não há nenhum privilégio, pois o significante não se cola ao significado, salientando que, quanto ao sentido, simboliza seu fracasso. Na seta que sai do lado masculino em direção ao feminino, percebemos que a ligação de \$ é com o objeto a, propondo que o homem só pode atingir seu parceiro sexual por intermédio deste ser a causa de seu desejo. Se é enquanto causa do desejo, objeto a, que o homem se dirige a uma mulher, é enquanto à "aparência do ser" que ele se dirige, na medida em que o a tem estatuto de semblante.

Lacan (1985/1972-73) aponta que essa conjunção (\$ e a), como ele já havia demonstrado em outra ocasião, não é outra coisa senão a fórmula da fantasia. Ou seja, para o homem, a relação com a mulher se reduz à fantasia. "O que se viu, mas apenas do lado do homem, foi que aquilo com o que ele tem a ver é com o objeto a, e que toda a sua realização quanto à relação sexual termina em fantasia." (Lacan,1985/1972-73, p. 116). Lacan complementa que, quando se é homem, a parceira é encarada baseando-se nele, em sua dimensão narcísica - sendo curioso que tal assertiva Freud tenha atribuido primitivamente à mulher. André (1998) diz que tal inscrição de Lacan indica que uma mulher só pode ser tomada por um homem, em última instância, como objeto parcial daquilo que seria o corpo do Outro. É por meio de um olhar, de uma voz, de uma pele, enfim, de partes do corpo mais ou menos fetichizadas que o homem goza e jamais (ao menos que se coloque em posição feminina) do corpo feminino como tal.

Do lado da mulher, Lacan (1985/1972-73) afirma que, a partir do momento em que ela é não-toda, o artigo " $A$ " tem que está barrado. $A$ inscrição também nos mostra que $\mathbb{A}$ mulher relaciona-se com 0 Outro - $S(\mathbb{A})$ - e com o falo - $\varphi$, indicando que a duplicação do gozo feminino se dá entre dois pólos, dos quais ela pode ter relação: com $S(\AA)$, enquanto aquilo que falta como significante no Outro; e, $\operatorname{com} \varphi$, mediante o que o homem pode encarnar para ela, sem, contudo, se ocupar inteiramente com ele. Sobre isso, Zucchi (2008) comenta que a mulher "simultaneamente demanda o falo, porém sem crer nele profundamente, já que a mulher goza também com o ilimitado do campo do Outro, $S\left(A^{A}\right) "$ (p. 89). Disso extraímos que a mulher tem seu gozo não-todo ocupado no homem, situando para além dele seu verdadeiro parceiro - $S(\mathbb{A})$. Todavia, conectar-se ao homem é a condição para ela ter acesso ao gozo não-todo. Nesse sentido, André (1998) comenta "Que a parte propriamente feminina do gozo se articule a $S(\mathbb{A})$ mais-além da contribuição fálica que faz do parceiro, quer dizer que uma mulher goza dela mesma enquanto Outra a ela mesma" (p. 224). A mulher, tal como o é para o 
homem, é Outro dela mesma; ela é para ela o próprio desconhecido, o não-todo.

É, nesse sentido, que podemos assinalar que a mulher desconhece aquilo que a faz não-toda. Parte de seu gozo está fora da linguagem e, portanto, nenhuma palavra pode ser dita sobre ele, logo, nada se sabe a seu respeito. Lacan (1985/1972-73) escreve que o que a mulher sabe é o fato de que ela experimenta esse gozo. Sobre esse gozo do qual não se pode emitir nenhuma palavra, Lacan o compara aos místicos ao afirmar que "o testemunho essencial dos místicos é justamente o de dizer que eles experimentam, mas não sabem nada dele." ( p. 103)

Sobre a mudez da mulher a respeito de seu gozo e a problemática inerente ao campo da sexuação, encerro a discussão com uma das versões do mito de Tirésias - que me parece bem oportuno. Se o mito nos serve é porque, como assinala Costa (2007), ele assume um papel de fazer borda, recortanto um lugar no qual o impossível pode de alguma maneira ser abordado.

Segundo Ruth Guimarães (1996), conta o mito que, Tirésias, foi orar sobre um monte e avistou um casal de cobras venenosas copulando, e ambas se voltaram contra ele. Tirésias matou a fêmea, e imediatamente se transformou em mulher, tornando-se uma prostituta famosa. Anos depois, indo orar sobre o mesmo monte, encontrou outro casal de cobras venenosas copulando. Desta vez, matou o macho e se transformou em homem, sendo assim, passou a ter o conhecimento sobre os dois sexos. Em função disso, por ocasião de uma discussão entre Zeus e Hera, sobre quem obteria mais prazer na relação sexual, se o homem ou a mulher, Tirésias foi chamado para decidir a questão. Ele sabia que, qualquer que fosse sua decisão, o deus que perdesse seria tomado de raiva contra ele. Hera dizia que o homem tinha mais prazer; Zeus dizia que era a mulher. Tirésias, sem muita escolha, respondeu a pergunta, afirmando que dividindo o prazer em dez partes, a mulher fica com nove e o homem com uma. Hera, furiosa por ter perdido, fez cair uma cegueira em Tirésias por vingança. Mas Zeus, compadecido e em recompensa por Tirésias ter dado a ele a vitória, concedeu-Ihe o dom da previsão.

Articulando o silêncio feminino sobre seu gozo e a posição de Hera frente a resposta de Tirésias, Pommier (1997) introduz uma questão: Por que Hera ficou tão furiosa com a revelação de seu segredo se ele Ihe confere um status superior no campo do gozo em compararão como o homem? Justamente porque esse prazer feminino não pode ser comparado ao do homem; ele é de outra ordem. Hera mostrouse enraivecida porque essa comparação a priva de uma diferença irredutível que the é própria. O gozo feminino não está situado no mesmo registro que o do homem, não permitindo tal comparação. Eis o impossível que Lacan formalizou. 


\section{Referências}

André, S. (1998). O que quer uma mulher? Rio de Janeiro: Jorge Zahar Editor.

Bonfim, F. \& Vidal, P. (2009). A feminilidade na psicanálise: a controvérsia quanto à primazia fálica. Fractal: Revista de Psicologia, 21(3), 539-548.

Brodsky, G. (2008). O homem, a mulher e a lógica. Latusa - Revista da Escola Brasileira de Psicanálise (EBP-Rio), (13), 171- 192.

Caldas, H. (2008). Saber fazer com a não-relação. In: S. Alberti (Org.), A sexualidade na aurora do século XXI (pp. 375-385). Rio de Janeiro: Companhia de Freud.

Costa A. (2007). A viagem de Ulisses. In A. Costa \& D. Rinaldi (Orgs.). Escrita e psicanálise (pp.353-360). Rio de Janeiro: Companhia de Freud, UERJ, Instituto de Psicologia.

Costa, A. (2008). Iniciação e saber na relação sexual. In S. Alberti (Org.), A sexualidade na aurora do século XXI (pp.307-314). Rio de Janeiro: Companhia de Freud.

Guimarães, R. (1996). Dicionário da mitologia grega. São Paulo: Editora Cultrix.

Lacan, J. (1998b). Diretrizes para um congresso sobre a sexualidade feminina. In Escritos (pp.734-748). Rio de Janeiro: Jorge Zahar Editor.

Lacan, J. (2003). O aturdito (1972). In J. Lacan, Outros Escritos (pp. 448-497). Rio de Janeiro: Jorge Zahar Editor.

Lacan, J. (2005). O Seminário 10 - a angústia (1962-63). Rio de Janeiro: Jorge Zahar Editor.

Lacan, J. (1985). O Seminário 20 - mais, ainda (1972-73). Rio de Janeiro: Jorge Zahar Editor.

Morel, G. (1997). Sexuação, Gozo e Identificação. Latusa - Revista da Escola Brasileira de Psicanálise (EBP-Rio), (1), 89-112.

Poli, M. C. (2008). A diferença sexual em psicanálise. In S. Alberti (Org.). A sexualidade na aurora do século XXI (pp.355-371). Rio de Janeiro: Companhia de Freud.

Rosa, M. (2001). "Essas coisas absolutamente heteróclitas." Opção Lacaniana - Revista Brasileira Internacional de Psicanálise, São Paulo, (31), p.56-59.

Rubião, L. (2006). A comédia e a ruptura dos semblantes: notas sobre "As nuvens", em liturraterra. Agora, 9(2), 259-271.

Soler, C. (2005). O que Lacan dizia das mulheres. Rio de Janeiro: Jorge Zahar Editor.

Zucchi, M. (2008). Sobre o sexo e os limites do semblante. Latusa Revista da Escola Brasileira de Psicanálise (EBP-Rio), (13), 85-94. 


\section{Endereço para correspondência}

\section{Flávia Bonfim}

Rua Dr. Borman, 23 sala 505, Centro, CEP 24020-320, Niterói - RJ, Brasil

Endereço eletrônico: flaviabonfimpsi@yahoo.com.br

Recebido em: 09/07/2012

Aceito para publicação em: 20/06/2013

Acompanhamento do processo editorial: Rita Maria Manso de Barros

\section{Notas}

* Psicóloga. Psicanalista. Mestre em Pesquisa e Clínica em Psicanálise (Uerj). Docente da Pós-graduação "Psicanálise e Saúde Mental" (Unilasalle). 